\title{
Ovarian Serous Tumor
}

National Cancer Institute

\section{Source}

National Cancer Institute. Ovarian Serous Tumor. NCI Thesaurus. Code C8431.

A benign, borderline, or malignant epithelial tumor of the ovary characterized by the presence of neoplastic epithelial cells that, in well differentiated tumors, resemble the epithelial cells of the fallopian tube and, in poorly differentiated tumors, show anaplastic features. Approximately thirty to fifty percent of the tumors are bilateral. Grossly, the better differentiated tumors consist of cystic masses, usually unilocular, containing a clear but sometimes viscous fluid. Papillary formations are often present. The more malignant tumors tend to be solid and invasive, with areas of necrosis and hemorrhage. 